\title{
Influence of Rice Husk Ash and Clay in Stabilization of Silty Soils Using Cement
}

\author{
Jack Widjajakusuma* and Hendo Winata \\ Department of Civil Engineering, Universitas Pelita Harapan, 15811 Tangerang, Indonesia.
}

\begin{abstract}
Soil stabilization is needed to enhance the strength of the soil. One popular method of soil stabilization is using cement. Due to the environmental issue, it is a need to reduce the application of cement and/or to replace partially the cement with other environmental-friendly compounds. One of these compounds is rice husk ash (RSA), which is agricultural wastes. The objective of this paper is to study the influence of RSA and clay as partial replacement to cement in soil stabilization of silt soil with high plasticity $(\mathrm{MH})$ using cement. The cement used was ordinary Portland cement, while the RHA was obtained by burning rice husk at temperature of $250^{\circ} \mathrm{C}$. The $\mathrm{MH}$ soil is stabilized with $4 \%$ cement, $4 \%$ cement and 3\% rice husk ash and 4\% cement, $3 \%$ RHA and $3 \%$ clay. The various tests were conducted on the pure and stabilized soils. Results have indicated that application of $4 \%$ cement, $3 \%$ RHA and $3 \%$ clay as silt soil stabilization is more favorable in increasing soil strength and reducing brittle behaviour of soil.
\end{abstract}

\section{Introduction}

Soils are the most important building materials because soils support all the loads of existing buildings. However, the properties of local soils are often not suitable for the requirements of particular buildings such in the case of many regions in Jakarta, Indonesia. To overcome those problematic soils, one has to enhance their properties. One method to improve the properties of soils is mixing and blending soils with other materials. These materials can be chemical mixers such as cement, rice husk ash, salt, lime, coal ash, asphalt cement, sodium, calcium chloride, paper mill waste and other chemicals [1-3].

The most common and widely used chemical mixer in soil stabilization is cement [1-3]. The reason for applying cement is that the cement is relatively easy to obtain. On the other hand, cement is not a renewable materials and cement production performs very high carbon emissions so that cement production is not environmentally friendly. Other disadvantages are the soil-cement are susceptible to cracks at high temperatures, brittle and corrosive. Furthermore, the price of cement is rapidly increasing due to the sharp increasing price of energy [4]. Therefore, many studies have been conducted to find an alternatives pozzolanas to total or partially replaced cement.

Pozzolona is a siliceous or siliceous and aluminous components which at room temperature and in the presence of water chemically reacts with calcium hydroxide to form cementitious materials.

This study applys rice husk ash (RHA), which contains $80-90 \%$ of amorphous silica [5], as alternatives pozzolona to partially replace the cement. RHA is a waste product abundantly available in rice producing countries such as Indonesia (the third-largest rice producing countries). Indonesia produced around 76 million tons of rice in 2015 [6] and will still increase the rice production in order to reach self-sufficiency in rice for Indonesian population.

One big issue in producing rice is the final disposition of rice husks, which are agricultural residues. The residues are huge and can be around $20 \%$ of total rice crop. In many regions in Indonesia, this rice residues are still treated as a waste product. To get rid of the waste, usually the farmers burn rice husks in the fields. Recently, rice husk is started to use as biomass. Burning of rice husks produces RHA, which is around $25 \%$ by weight of rice husk. Due to the low bulk density of RHA, disposition of RHA can be problematic to the land and human health.

The RHA contains large amount of amorphous silica. Amorphous silica has a wide range of applications such as silica gels, silicon chip, cement, catalysts. Due to the low cost and renewable of the RHA, it is worth to study the applications of the silica extracted from the RHA. Furthermore, the results of the study will also help to reduce the amount of RHA waste.

The previous studies with RHA had shown that it had promising potentials of improving the engineering properties of soils and inexpensive ([7-11]). However, RHA cannot be used alone because it has inadequate cementation property, which is required to bind the material to a satisfactory durability [10-11].

\footnotetext{
Corresponding author: jack.widjajakusuma@uph.edu
} 
Thus, this study focused on investigating the influence of adding RHA and the optimum amount of RHA on improving the engineering properties of silty sands. In order to reduce the brittleness of cementation soils, a small amount of natural clay was added. Clay had been chosen because it contained a lot of alumina and silica and had high plasticity. Thus, the present work study the influence of adding RHA and clay on modifying the engineering properties of silty sands. This work also investigated the effect of mechanical compaction in improving the soil properties.

\section{Materials}

The materials used in this study are described as follows:

\subsection{Soil specifications}

For the investigations of this work, typical soil found in West Jakarta such as silty soils. The soil colour was brown. Index properties of investigated soil have been summarized in Table 1. The soil was classified as silt with high plasticity MH in the USCS soil classification system.

Table 1. Summarizes the various index properties of investigated soil

\begin{tabular}{|l|l|l|lr|}
\hline $\begin{array}{l}\text { Water Content } \\
(\%)\end{array}$ & Specific gravity & Liquid limit (\%) & $\begin{array}{l}\text { Plastic limit } \\
(\mathbf{\%})\end{array}$ & \\
\hline 53.084 & 2.631 & 73.3 & 53.021 & \\
\hline
\end{tabular}

\subsection{Admixtures}

The admixtures used in this study were cement, RHA and clay. The cement used in this study was ordinary portland cement of type 1 . The rice husk was collected from Tangerang. The RHA was obtained by burning the rice husk in a cylindrical furnace at temperature $250^{\circ} \mathrm{C}$. Then, the RHA was grounded with Los Angeles machine and sieved through $0.075 \mathrm{~mm}$ aperture before use. The chemical contents of RHA was given in Table 2 . The natural clay used in this study was black clay and was collected from Karawang.

Table 2. Summarizes the chemical properties of RHA

\begin{tabular}{|l|l|l|}
\hline $\mathrm{SiO}_{2}[\%]$ & $\mathrm{Fe}_{2} \mathbf{O}_{3}[\%]$ & $\mathbf{A l}_{2} \mathbf{O}_{3}[\%]$ \\
\hline 95 & 1.48 & 2.21 \\
\hline
\end{tabular}

\section{Methods of testing}

To study the effect of mixing on soil, various laboratory tests were carried out. To study the index properties of soil and its mixtures, particle size distribution and Atterberg limit tests were conducted. To study the engineering properties of soil and its mixtures, California Bearing Ratio (CBR) and triaxial tests were performed. The geotechnical properties of the soil were determined according to ASTM [12].

The laboratory tests carried out first were on the pure soil. Then, the tests were carried out for the soil samples mixed with 4\% cement; 4\% cement and 3\% RHA; 4\% cement, 3\% RHA and 3\% clay. The following abbreviations were used $4 \% \mathrm{C}$ for mixtures of soil with 4\% cement, 4\% C 3\% RHA for mixtures of soil with 4\% cement, 3\% RHA, 4\% C 3\% RHA 3\% Clay for mixtures of soil with 4\% cement, 3\% RHA and 3\% clay.

The sample for testing had been prepared in accordance with the requirement of the tests. First, the pulverized soil sample was sieved through the required sieve. The required amount of soil was weighed out for the particular test. The admixture was also sieved through the required sieve and the required amount was weighed out on the weight basis according to the percentage to be added to the soil for the particular test. Then, the soil and admixtures were mixed throughly to ensure homogeneous distribution of the admixtures in the soil. These mixture samples were used for performing the various tests.

\section{Results and discussion}

\subsection{Effect of admixtures on particle size distribution}

The range of particle sizes in soils was very large, so the logarithmic scale had been used. Figure 1 shows the particle size curve as percent finer vs. log of particle size. The cement was found to have effect on the grain size of stabilized soil, which can be seen from Fig. 1. The reason was that soil and cement reaction form cementitious compounds in the soil. Consequently, the grain size of the stabilized soils, which contained lesser cement, were lesser modified. This can be clearly seen from Fig. 1 . The grain size of stabilized soil with $4 \%$ cement was most modified, comparing to other stabilized soils. 


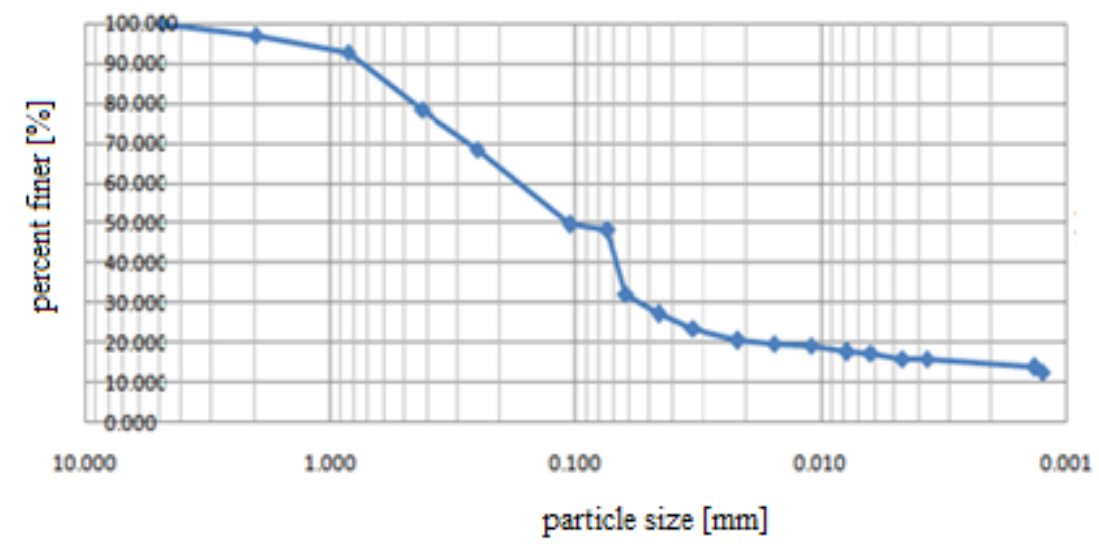

(a) Pure soil

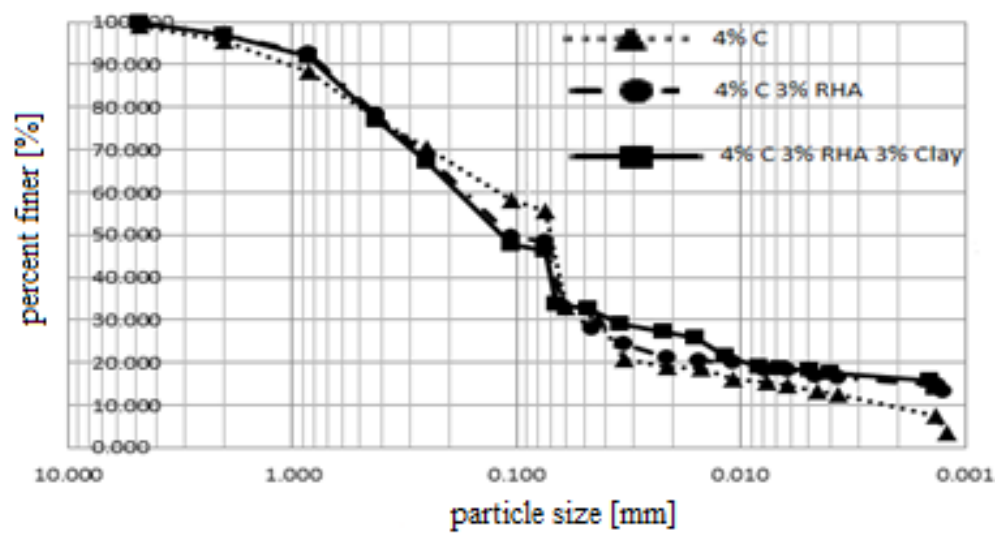

(b). Stabilized soils

Fig. 1. Particle size distribution of (a) pure soil and (b) stabilized soils

\subsection{Effect of admixtures on plasticity}

The plasticity index (PI) of pure soil was approximately $20.31 \%$. As the silty soil was mixed with cement, cement and RHA, the PI becomes 0 (non-plastic soil). The reason was that soil, cement and RHA reaction produce cementitious soils, which decreased the Atterberg limits to a greater extent [13-14]. Applying the small amount of clay in soil mixtures with cement and RHA decreased the liquid limit (LL) and PI. However, the value of LL and PI of stabilized soil with $4 \% \mathrm{C} 3 \%$ RHA 3\%Clay were higher than those of stabilized soils with $4 \% \mathrm{C}$ and $4 \% \mathrm{C} 3 \%$ RHA. In general, a reduction of the PI value indicated the improvement of the soil.

Table 3. Summarizes the Atterberg limits

\begin{tabular}{|l|l|l|l|l|}
\hline & pure soil $[\%]$ & $\begin{array}{l}\mathbf{4 \% C} \\
{[\%]}\end{array}$ & $\begin{array}{l}\mathbf{4 \% C ~ 3 \% R H A ~} \\
{[\%]}\end{array}$ & $\mathbf{4 \% C ~ 3 \% R H A ~ 3 \% C l a y ~ [ \% ] ~}$ \\
\hline LL & 73.33 & 43.12 & 35.77 & 51.43 \\
\hline PL & 53.02 & - & - & 46.03 \\
\hline PI & 20.31 & - & - & 5.40 \\
\hline
\end{tabular}

\subsection{CBR tests results}

CBR tests, which is common used in the design of base and sub-base material for pavement, had been conducted to evaluate the strength of stabilized soils. In order to study the effect of soaking, the samples had been grouped in three groups. The first, second and third group of samples were soaked in water for 3 days, 7 days and 14 days, respectively. Each group had two series of soil samples. The first series consisted of pure soil, stabilized soils 4\% C; 4\%C 3\%RHA and 4\%C 3\%RHA 3\%Clay, which were compacted with 25 blows. The second series consisted of pure soil, stabilized soils 4\% C; 4\%C 3\%RHA and 4\%C 3\%RHA 3\%Clay, which were compacted with 56 blows.

Table 4 gives the results of CBR tests for pure soil. The soaked CBR values of pure soil decrease with increasing soaking days. The CBR values increased with increasing number of blows. These results had confirmed that water reduced the strength of the soil, meanwhile, the compaction raised the strength of the soil.

Figure 2 shows the results of all CBR tests for the stabilized soils. The CBR values of all samples increased with increasing the soaking days and increasing the number of blows. 
The reason for increasing in CBR values of stabilized samples might be because of the gradual formation of cementitious compounds in the soil by the reaction between the cement and RHA with the water.

Table 4. Summarizes CBR values of pure soil

\begin{tabular}{|c|c|c|}
\hline Soaked [days] & Blows & CBR (\%) \\
\hline 3 & 25 & 0.476 \\
\hline 7 & 25 & 0.458 \\
\hline 14 & 25 & 0.426 \\
\hline 3 & 56 & 0.547 \\
\hline 7 & 56 & 0.469 \\
\hline 14 & 56 & 0.447 \\
\hline
\end{tabular}

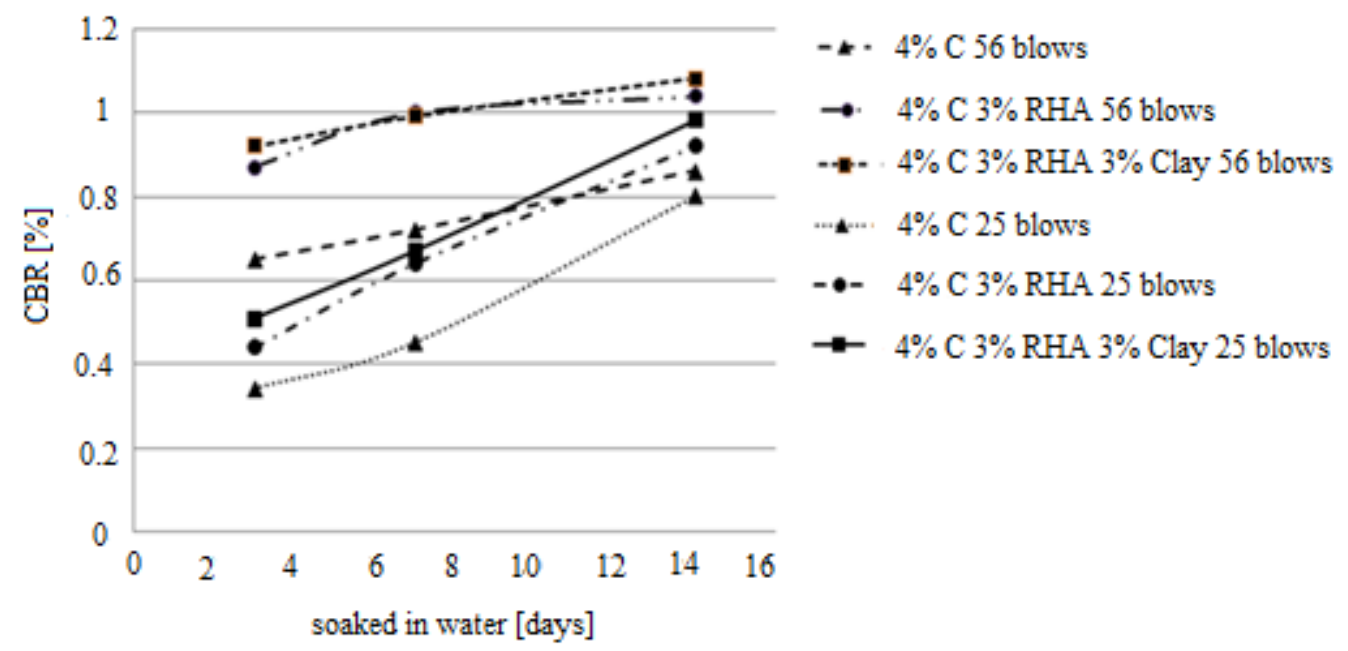

Figure 2. Results of CBR tests

\subsection{Triaxial test results}

Triaxial tests has been performed on samples without and with admixtures for 3, 7 and 14 days curing. Table 5 shows the development of cohesion intercept $\mathrm{c}$ and internal friction angle $\phi$. Adding admixtures to the soil caused an increase in cohesion and internal friction angle. The reason was that soil and cement reaction form cementitious compounds in the soil.

Table 5. Summarizes cohesion intercept $\mathrm{c}$ and friction angle $\phi$

\begin{tabular}{|c|c|c|c|c|c|c|c|c|c|}
\hline \multirow[t]{2}{*}{ Blows } & \multirow[t]{2}{*}{ days } & \multicolumn{2}{|l|}{ pure soil } & \multicolumn{2}{|l|}{$4 \% \mathrm{C}$} & \multicolumn{2}{|c|}{ 4\%C 3\%RHA } & \multicolumn{2}{|c|}{$\begin{array}{l}\text { 4\%C 3\%RHA } \\
3 \% \text { Clay }\end{array}$} \\
\hline & & $\begin{array}{c}c \\
{\left[\mathrm{kN} / \mathbf{m}^{2}\right]}\end{array}$ & $\phi\left[^{\circ}\right]$ & $\begin{array}{c}c \\
{\left[\mathrm{kN} / \mathrm{cm}^{2}\right]}\end{array}$ & $\begin{array}{c}\phi \\
{\left[{ }^{\circ}\right]}\end{array}$ & $\begin{array}{c}c \\
{\left[\mathrm{kN} / \mathbf{m}^{2}\right]}\end{array}$ & $\begin{array}{c}\phi \\
{\left[{ }^{\circ}\right]}\end{array}$ & $\begin{array}{c}c \\
{\left[\mathrm{kN} / \mathrm{m}^{2}\right]}\end{array}$ & $\phi\left[{ }^{\circ}\right]$ \\
\hline \multirow[t]{3}{*}{25} & 3 & 34.4 & 17.18 & 30.7 & 29 & 49.4 & 28 & 49.8 & 27 \\
\hline & 7 & 30.9 & 17.12 & 33.3 & 29.5 & 52.2 & 29 & 71. & 28 \\
\hline & 14 & 28.8 & 16.73 & 38.2 & 30 & 59.9 & 29.5 & 74.5 & 29 \\
\hline \multirow[t]{3}{*}{56} & 3 & 40.8 & 17.31 & 36.4 & 37 & 60.9 & 32 & 89.6 & 29 \\
\hline & 7 & 31.4 & 17.30 & 60.9 & 38 & 69.4 & 37 & 92.0 & 29.5 \\
\hline & 14 & 31.1 & 16.77 & 89.6 & 39 & 70.6 & 38.5 & 101.0 & 30 \\
\hline
\end{tabular}

The strength of pure soil decreased with increasing soaking days. These results have confirmed that water reduces the strength of the soil. Meanwhile, the strength of stabilized soils increased with increasing soaking days. The reason for increasing of the strength of stabilized soils might be because of the gradual formation of cementitious compounds in the soil by the reaction between the cement, the cement and RHA with the water. The highest soil strength has achieved for the combination of soil, RHA and clay. By increasing the number of blows (compaction) raised the strength of the soil. 


\section{Conclusions}

The results in this paper can be summarized as follows:

- The soft soil was classified as to be silt of high plasticity (MH) in accordance with USCS classified system. Since the soil wass very low, which wass indicated by very low CBR value (below 1\%), the soil was needed to be stabilized.

- Compaction, indicating by increasing the blows, had increased the strength of the pure soil and stabilized soils by around $100 \%$.

- All of the stabilized soils after soaking of 14 days had increased the CBR value by around $100 \%$.

- Treatment with $4 \%$ cement had increased the cohesion value of stabilized soil from $28.8 \mathrm{kN} / \mathrm{m}^{2}$ to $38.2 \mathrm{kN} / \mathrm{m}^{2}(25$ blows, 14 soaked days) and from $31.1 \mathrm{kN} / \mathrm{m}^{2}$ to $89.6 \mathrm{kN} / \mathrm{m}^{2}$ (56 blows, 14 soaked days). This treatment also increased the value of the internal friction angle from $16.73^{\circ}$ to $30^{\circ}$ (25 blows, 14 soaked days) and $16.77^{\circ}$ to $39^{\circ}(56$ blows, 14 soaked days).

- $\quad$ Treatment with $4 \%$ cement $3 \%$ RHA had increased the cohesion value of stabilized soil from $28.8 \mathrm{kN} / \mathrm{m}^{2}$ to 59.9 $\mathrm{kN} / \mathrm{m}^{2}$ (25 blows, 14 soaked days) and from $31.1 \mathrm{kN} / \mathrm{m}^{2}$ to $70.6 \mathrm{kN} / \mathrm{m}^{2}$ (56 blows, 14 soaked days). This treatment had also increased the value of the internal friction angle from $16.73^{\circ}$ to $29.5^{\circ}$ ( 25 blows, 14 soaked days) and $16.77^{\circ}$ to $38.5^{\circ}$ (56 blows, 14 soaked days).

- Treatment with 4\% cement 3\% RHA and 3\% Clay had increased the cohesion value of stabilized soil from 28.8 $\mathrm{kN} / \mathrm{m}^{2}$ to $74.5 \mathrm{kN} / \mathrm{m}^{2}$ (25 blows, 14 soaked days) and from $31.1 \mathrm{kN} / \mathrm{m}^{2}$ to $101.0 \mathrm{kN} / \mathrm{m}^{2}$ (56 blows, 14 soaked days). This treatment had also increased the value of the internal friction angle from $16.73^{\circ}$ to $29^{\circ}$ ( 25 blows, 14 soaked days) and $16.77^{\circ}$ to $30^{\circ}$ (56 blows, 14 soaked days).

- Combining the compaction and stabilization of the silt soil had increased the soil strength by around $250 \%$.

- After the stabilizing, the CBR values were still low, thus, the soils had to be modified.

- Soil stabilization applying RHA in rice-producing countries such as Indonesia is attractive because it reduces the construction cost, especially in the remote area. Furthermore, this method helps to reduce the waste of rice husk and RHA and preserves non-renewable resources such as cement.

The first author sincerely thanks to the University of Pelita Harapan, who provided partially funding for this study. He would also like to recognize DAAD for support during the short visit at Ruhr-University Bochum and some fruitful discussions with Prof. Dr.Ing. H. Steeb during the stay.

\section{References}

1. R.H. Karol, Chemical Grouting and Soil Stabilization, Revised and Expanded. CRC Press, Boca Raton (2003).

2. K. Kirsch and A. Bell, Ground Improvement, CRC Press, Boca Raton (2013).

3. P.G. Nicholson, Soil Improvement and Ground Modification Methods, Elsevier, Amsterdam (2015).

4. A.M. Neville, Properties of Concrete, Pearson, Singapore (2000).

5. D.F. Houston, In: Rice: Chemistry and Technology, American Association of Cereal Chemists, 301-340 (1972).

6. Badan Pusat Statistik (Statistics Indonesia), Produksi Padi, Jagung, dan Kedelai (Angka Sementara Tahun 2015) (Production of paddy, maize and soybeans (Preliminary Figures 2015)). Jakarta, Indonesia.

7. R. Pode, Renewable and Sustainable Energy Rev, 53, 1468-1485 (2016).

8. K.M.A. Hossain, J. Mat. in Civil Eng., 23, 1320-1327 (2011).

9. T.R. Karatai, J.W. Kaluli, C. Kabubo and G. Thiong'o, J. Constr. Eng. Manage. DOI: 10.1061/(ASCE)CO.19437862.0001235 (2016)

10. D.G. Nair, K.S. Jagadish and A. Fraaij, Cement and Concrete Res., 36, 1062-1071 (2006).

11. F.H. Ali, A. Adnan and C.K. Choy, Geotech. And Geological Eng., 10, 117-134 (1992).

12. A.W. Al-Khafaji and O.B. Andersland, Geotechnical Engineering and Soil Testing, Saunders College Publishing, Fort Worth (1992).

13. T.T. Hensley, Pozzolan stabilized subgrades, Research Project SPR-I (06) 578, Nebraska Dept. of Roads, Lincoln, NE.

14. M.Y. Fattah, F.H. Rahil and K.Y.H. Al-Soudany, J. Civ. Eng. Urban, 3, 12-18 (2013) 